\title{
Sarcoma de células dendríticas foliculares extranodal
}

\author{
Extranodal follicular dendritic cell sarcoma
}

Lina Gomes dos Santos'; José Alexandre Leal Borges²; Thiago de Brito Ribeiro ${ }^{3}$

\begin{abstract}
unitermos resumo
Sarcoma

O sarcoma de células dendríticas foliculares (SCDF) é uma neoplasia maligna rara que envolve linfonodos

Célula dendrítica folicular

e sítios extranodais. Pode exibir variado aspecto histológico e comportamento clínico, mas usualmente

Linfonodos

apresenta um curso agressivo. Relatamos um caso de sarcoma de células dendríticas foliculares em um paciente de 37 anos de idade, do sexo masculino, em topografia de tonsila palatina esquerda, que se apresentava como abaulamento e edema em trígono retromolar esquerdo. O exame clínico evidenciou lesão tumoral ulcerada e o estudo tomográfico mostrou lesão bem delimitada em região parafaríngea à esquerda. Foi submetido a duas biópsias incisionais que foram inconclusivas, sendo então realizada ressecção cirúrgica da lesão com ampliação para a tonsila palatina esquerda adjacente. O estudo histopatológico do espécime revelou neoplasia maligna constituída por proliferação de células fusiformes, e o estudo imuno-histoquímico confirmou o diagnóstico. O SCFD deve ser considerado no diagnóstico diferencial de qualquer neoplasia de células fusiformes com infiltrado inflamatório crônico de permeio surgindo em região de cabeça e pescoço. Esta lesão exibe padrões histológicos peculiares que permitem um diagnóstico presuntivo, sendo que o diagnóstico final requer confirmação através de métodos especiais.
\end{abstract}

\section{abstract}

Follicular dendritic cell sarcoma (FDCS) are uncommon malignant neoplasms that can involve lymph nodes or extranodal sites. They can exhibit a broad spectrum of histologic appearences and behavior, but usually pursue an aggressive course. A case of follicular dendritic cell sarcoma arised in the tonsil region is reported in a 37-year-old man. He had a swelling in the left retromolar trigone. Clinical examination disclosed an ulcerated mass. CT scans showed a low density lesion in the left medial parapharyngeal area. The biopsy specimen was insatisfatory and the patient underwent successful surgical excision of the tumor which was extended to palatine tonsil adjacent and right palatine tonsil. The specimen revealed a low grade malignant tumor and immunohistochemical has confirmed the diagnosis. FDCS should be considered in the differential diagnosis of any spindled cell tumor with interspersed chronic inflammatory cells occurring in head and neck regions. This tumor exhibits distinctive histologic features that permit its presumptive diagnosis, but a final diagnosis requires confirmation with special studies. key words

Sarcoma

Follicular dendritic cell

Lymph nodes

\section{Introdução}

O sarcoma de células dendríticas foliculares (SCDF) é uma neoplasia maligna rara que exibe diferenciação para células foliculares dendríticas. Mais freqüentemente acomete linfonodos, mas pode acometer também sítios extranodais ${ }^{(1,2,8)}$.
As células foliculares dendríticas neoplásicas exibem o mesmo perfil morfológico e imunofenotípico das células foliculares dendríticas não-neoplásicas que residem normalmente nos centros germinativos. Tal lesão ocorre em adultos, não tem predileção por sexo e habitualmente se apresenta como linfadenopatia cervical indolor de crescimento lento não-associada a

1. Mestranda em Ciências e Saúde pela Universidade Federal do Piaú (UFPI); professora da disciplina de Patologia Ceral da UFPl; patologista do Hospital São Marcos, em Teresina (PI).

2. Professor substituto da disciplina de Oncologia da Faculdade de Ciências Médicas da Universidade Estadual do Piaú (UESPI); médico-cirurgião de cabeça e pescoço do Hospital São Marcos.

3. Acadêmico de Medicina da UFPI.

Trabalho realizado no setor de Patologia do Hospital São Marcos. 
sintomas sistêmicos ${ }^{(13)}$. Entre os sítios extranodais, os mais comumente afetados são palato mole, tonsilas, baço, trato gastrointestinal, fígado e partes moles ${ }^{(8,13)}$.

\section{Relato de caso}

Paciente do sexo masculino, 37 anos de idade, procurou o Serviço de Cirurgia de Cabeça e Pescoço deste hospital, em setembro de 2000 , referindo que há quatro meses notou tumoração na base da língua, com dor local e dificuldade de deglutição, sem outras queixas. Feita laringoscopia direta, evidenciando-se lesão tumoral em loja amigdaliana esquerda, que se projeta para a luz da orofaringe e ainda linfonodo cervical esquerdo com $3 \mathrm{~cm}$ de diâmetro, móvel e indolor.

Foram realizadas duas biópsias, que se mostraram inconclusas. O paciente foi, então, submetido a ressecção cirúrgica completa da lesão em outubro de 2000 (Figura 1). O estudo histopatológico do espécime revelou neoplasia maligna constituída por células fusiformes, e o estudo imuno-histoquímico confirmou o diagnóstico (Tabela).

Em fevereiro de 2001, retornou com queixa de crescimento das lesões cervical e em cavidade oral. Ao exame, houve crescimento da lesão em cavidade oral, na loja amigdaliana, com extensão para o palato mole. A tomografia computadorizada (TC) mostrou lesão expansiva sólida, de aspecto neoplásico, localizada em espaço oronasofaríngeo à esquerda, obliterando o recesso lateral da faringe. Tal lesão ocupava mais de $50 \%$ da orofaringe e do palato mole (Figura 2). Havia também linfonodo cervical com $3 \mathrm{~cm}$, sem outras adenopatias periféricas palpáveis. A TC de abdome revelou leve esplenomegalia, e o raio $\mathrm{X}(\mathrm{RX})$ de tórax não revelou alterações.

O paciente foi encaminhado à quimioterapia (QT), tendo sido realizado o primeiro ciclo (CHOP + bleomicina).

Em março de 2001, ele retornou para consulta, quando pouca regressão tumoral foi constatada. Foi realizado,

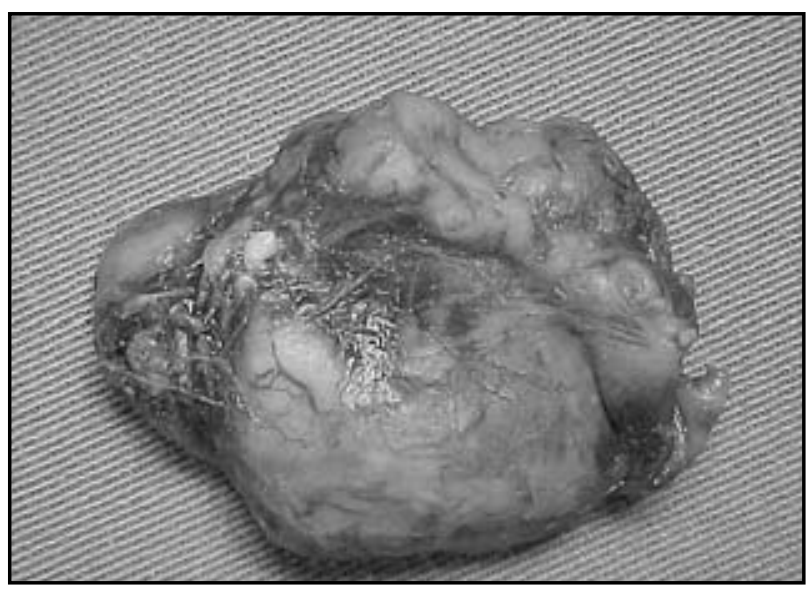

Figura 1 - Macroscopia: superfície externa do SCDF então, o segundo ciclo de QT com encaminhamento para o serviço de radioterapia, onde se fez uma sessão com regressão tumoral de $50 \%$. Em maio, voltou com tomografia cervical mostrando lesão de $7 \times 6,8 \times 5,2 \mathrm{~cm}$, indo desde a base do crânio até a hipofaringe (seio piriforme) com linfadenomegalia cervical bilateral $(2 \mathrm{~cm})$.

Em agosto, regressou com queixa de zumbido e tonturas. A ressonância nuclear magnética (RNM) mostrou lesão heterogênea expansiva desde a rinofaringe até a hipofaringe (seio piriforme, palato mole/duro/base da língua/loja amigdaliana e espaço retrofaríngeo esquerdo) com extensão para a fossa craniana, comprometimento extradural e mastoidite crônica esquerda. RX de tórax sem alterações e ultra-sonografia (US) abdominal revelando leve esplenomegalia. Foi novamente encaminhado para a QT. Em setembro, queixou-se de aumento da hemiface esquerda, tendo sido evidenciada progressão tumoral. Foi realizado o terceiro ciclo de QT em 05/09/2001. Observouse menos de $50 \%$ de redução tumoral. Partiu-se, então, para o quarto ciclo de QT.

\section{Tabela Painel imuno-histoquímico}

\begin{tabular}{lc}
\hline Anticorpo & Resultado \\
EMA (antígeno de membrana epitelial) & Positivo \\
Pancitoceratinas (AE1/AE3) & Negativo \\
CAM 5.2 & Negativo \\
Desmina & Negativo \\
HHF 35 (actina de músculo liso) & Negativo \\
CD23 & Positivo \\
CD35 & Positivo \\
CD21 & Negativo \\
CD45 (antígeno leucocitário comum) & Negativo \\
CD44 & Negativo \\
Proteína S100 & Negativo \\
\hline
\end{tabular}

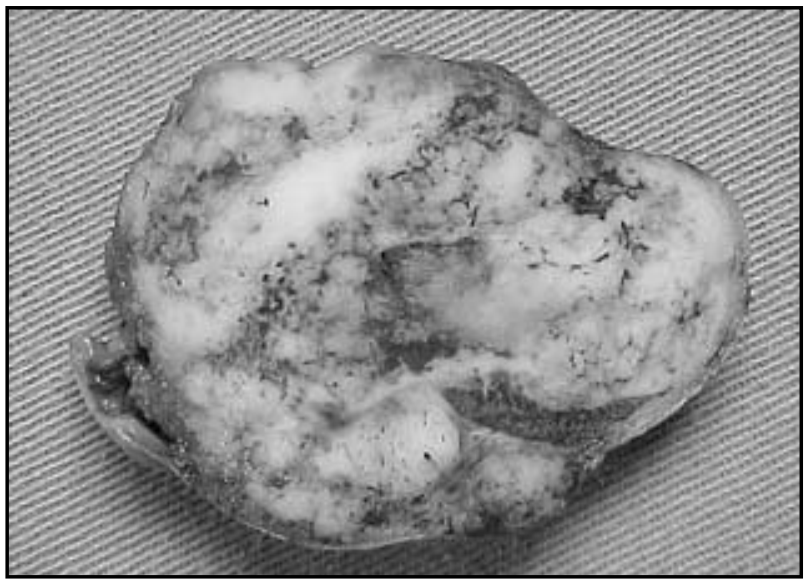

Figura 2 - Macroscopia: superfície de corte do SCDF 
Em novembro, uma tomografia cervical (Figura 3) mostrou lesão sólida ocupando rino e orofaringe, hipofaringe, estendendo-se desde o teto da rinofaringe até a borda superior da epiglote, com extensão intracraniana e extraaxial, obliterando mais de $95 \%$ da luz da orofaringe e mais de $80 \%$ da luz do seio piriforme, associada a linfadenopatia submentoniana esquerda. Houve progressão tumoral após o quarto ciclo de QT. O paciente recusou-se a realizar novos ciclos. Em março de 2002, apresentou múltiplas metástases pulmonares com derrame pleural, evoluindo ao óbito por insuficiência respiratória aguda.

\section{Discussão}

O SCDF é uma neoplasia maligna extremamente incomum, surgida mais freqüentemente em linfonodos cervicais. Têm sido descritos, porém, casos de localização extranodal, em especial região de cabeça e pescoço. Tal neoplasia tem importância devido ao seu baixo índice de suspeição tanto pelo clínico quanto pelo patologista. Até o ano de 2000, tinham sido descritos 34 casos deste tumor na região de cabeça e pescoço, sendo que 25 deles eram em linfonodos cervicais, quatro em tonsilas, dois no palato, um na faringe, um parafaríngeo e um em tireóide ${ }^{(12)}$.

Há ampla variação etária, com predomínio em pacientes adultos, não existindo predomínio em nenhum dos sexos. Em $10 \%$ a $20 \%$ dos casos, está associado a doença de Castleman, geralmente do tipo hialino-vascular, sendo que esta pode ser concomitante ou preceder o $\operatorname{SCDF}^{(8)}$.

O comprometimento nodal é visto em $30 \%$ a $50 \%$ dos casos, com os linfonodos cervicais sendo mais freqüentemente comprometidos, seguidos pelos linfonodos axilares, mediastinais, mesentéricos e retroperitoneais. Entre os sítios extranodais mais comumente acometidos temos tonsilas, baço, cavidade oral, trato gastrointestinal, fígado, partes moles, pele e mama ${ }^{(8)}$. Tal lesão pode se metastatizar, sendo que mais freqüentemente o faz para linfonodos regionais,

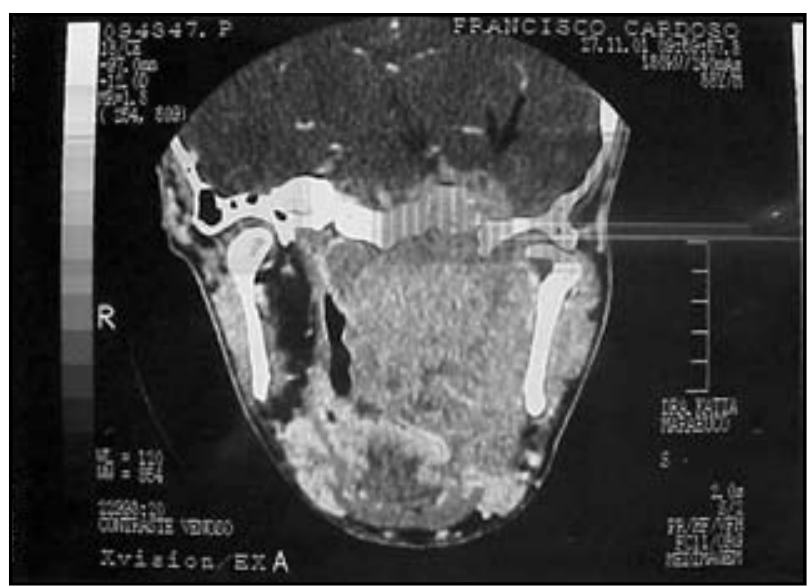

Figura 3 - Tomografia computadorizada pulmão e fígado. O paciente aqui descrito desenvolveu metástases pulmonares múltiplas com derrame pleural, evoluindo ao óbito em um ano e meio após o diagnóstico.

Em elevada porcentagem há associação com o vírus Epstein-Barr, e, nestes casos, o RNA viral tem sido encontrado em todas as células fusiformes neoplásicas.

Macroscopicamente as lesões variam de 1 a $20 \mathrm{~cm}$, com o tamanho médio de $5 \mathrm{~cm}$. As lesões menores têm sido descritas em linfonodos, e aquelas que formam massas tumorais volumosas, em retroperitônio.

Microscopicamente, tal neoplasia é constituída por proliferação de células fusiformes neoplásicas dispostas em fascículos curtos, em arranjo estoriforme ou enrodilhado, similar ao visto nos meningeomas, com células inflamatórias de permeio. Espaços císticos perivasculares preenchidos por fluido, similar ao timoma, também têm sido descritos. As células tumorais individuais exibem citoplasma arredondado e eosinofilico com bordos indistintos. O núcleo é vesiculoso, com cromatina fina e bem distribuída e nucléolo pequeno e evidente. Mitoses e necrose são incomuns. Há ainda, de permeio, células gigantes multinucleadas, lembrando células de Warthin-Finkeldey, bem como pseudo-inclusões intranucleares.

O caso aqui apresentado exibia apresentação clínica sugestiva, pois se tratava de localização relativamente comum e morfologia característica da neoplasia, sendo que o painel imuno-histoquímico clássico confirmou o diagnóstico definitivo.

O paciente foi submetido a quimio e radioterapia com pouca resposta, havendo recidiva tumoral mesmo após a ressecção cirúrgica completa da lesão. A recidiva exibia uma apresentação clínica mais agressiva, embora o aspecto morfológico permanecesse absolutamente o mesmo.

Entre os diagnósticos diferenciais morfológicos temos o timoma e o miofibroblastoma em paliçada do linfonodo. No primeiro, a presença de corpúsculos de Hassall e a positividade imunoistoquímica para citoceratinas nas células fusiformes fazem o diagnóstico. O miofibroblastoma em paliçada, que se trata de lesão benigna acometendo preferencialmente linfonodo inguinal, exibe, de permeio, as típicas fibras amiantóides. O principal diagnóstico diferencial, porém, se faz com o sarcoma de células dendríticas interdigitantes, sendo que o aspecto morfológico é indistinto e o imunofenotípico faz o diferencial, pois exibe imunorreatividade para proteína S100 e vimentina e negatividade para marcadores das células dendríticas foliculares $\left(\mathrm{CD} 21, \mathrm{CD} 23\right.$ e CD35) ${ }^{(8)}$.

A cirurgia tem sido a principal abordagem terapêutica para esta neoplasia e deve incluir rigorosa avaliação das margens cirúrgicas. $O$ papel da terapia adjuvante (quimio ou radioterapia) ainda permanece controverso ${ }^{(12)}$. 


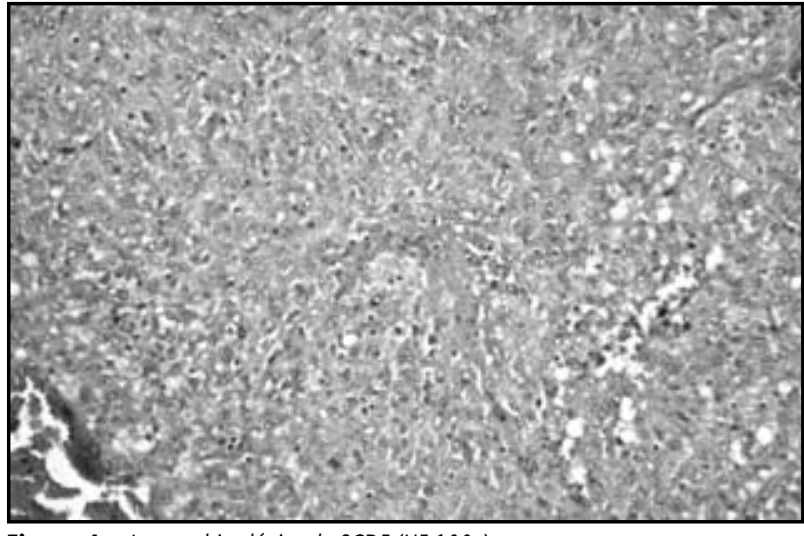

Figura 4 - Aspecto histológico do SCDF (HE 100x)

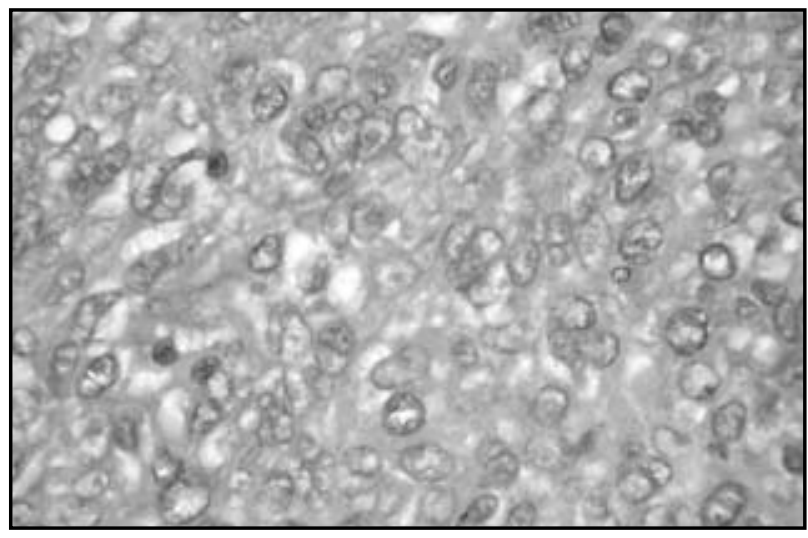

Figura 6 - Detalhe da célula neoplásica do SCDF (HE 400x)

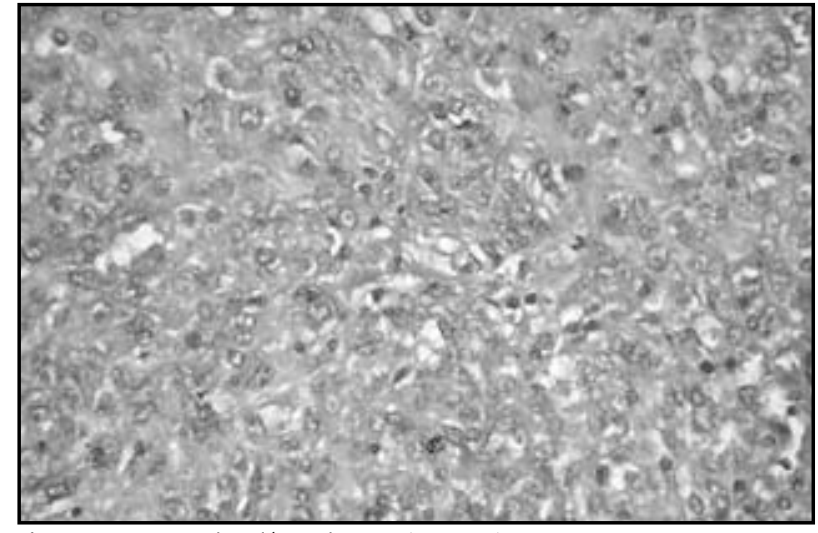

Figura 5 - Aspecto histológico do SCDF (HE 200x)

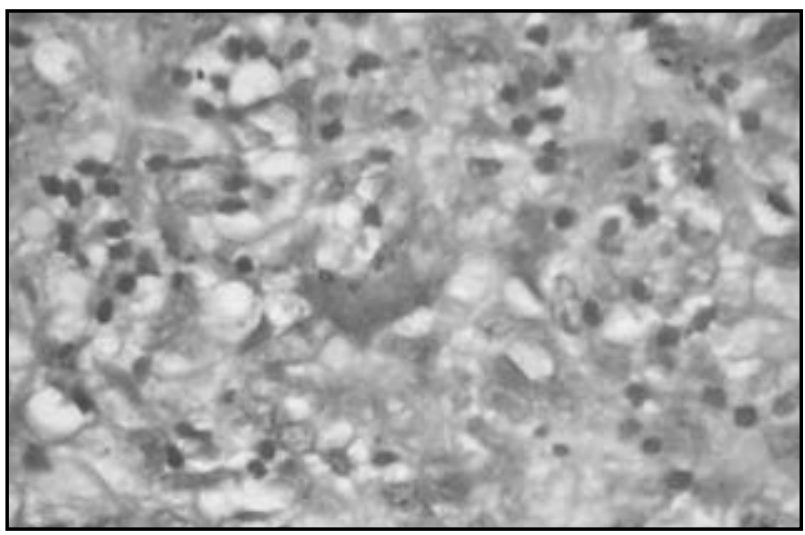

Figura 7 - Detalhe da célula de Warthin-Finkeldey (HE 400x)

\section{Referências}

I. CHAN, J. K. et al. Follicular dendritic cell tumors of the oral cavity. Am J Surg Pathol, v. 18, n. 2, p. 1480-57, 1994.

2. CHAN, J. K. et al. Follicular dendritic cell sarcoma. Clinicopathologic analysis of 17 cases suggesting a malignant potential higher than currently recognized. Cancer, v. 79, n. 2, p. 294-313, 1997.

3. CHEN, T. C. et al. Follicular dendritic cell tumors of the liver: a clinicopathologic and Epstein-Barr virus study of two cases. Mod Pathol, v. I4, n. 4, p. 354-60, 200 I.

4.DESAI, S. et al. Follicular dendritic cell tumors of the parapharyngeal region. Head Neck, p. 164-7, 1999.

5. FASSINA,A. et al. Follicular dendritic cell tumor of the mediastinum. Ann Diagn Pathol, v. 5, n. 6, p. 36I-7, 200 I.

6. HANGAI, K. et al. Follicular dendritic cell tumor of the cervical lymph node. ORL J Otorhinolaryngol Relat Spec, v. 64, n. 3, p. 229-32, 2002.

7. HAN, J. H. et al. Follicular dendritic cell sarcoma presenting as a submucosal tumor of the stomach. Arch Pathol Lab Med, v. 124, n. II, p. 1693-6, 2000.
8. INTERNATIONAL AGENCY FOR RESEARCH ON CANCER (WHO). Tumours of Haematopoietic and Lymphoid Tissues. Lyon: IARC, 200 I. p. 286-9.

9. PEREZ-ORDONEZ, B. et al. Follicular dendritic cell tumor: report of I 3 additional cases of a distinctive entity. Am J Surg Pathol, v. 20, n. 8, p. 944-55, 1996.

I0. SATOH, K. et al. Follicular dendritic cell tumor in the oropharyngeal region: report of a case and a review of the literature. Oral Oncol, v. 39, n. 4, p. 4I5-9. 2003.

I I. SHAH, R. N. et al. Follicular dendritic cell tumor presenting in the lung: a case report. Hum Pathol, v. 32, n. 7, p.745-9, 2001.

12.VARGAS, H. et al. Follicular dendritic cell tumor: an aggressive head and neck tumor. Am J Otolaryngol, v. 23, n. 2, p. 93-8, 2002.

I3. WEISS, L. M; Chang K. L. Histiocytic and dendritic cell proliferations. In:WEISS, L. M. (ed.) Pathology of lymph nodes. Nova York: Churchill Livingstone Inc., 1996. p. 4I3-6.

\begin{tabular}{l|l} 
& Endereço para correspondência \\
\hline & Lina Comes dos Santos \\
Av. Barão de Gurguéía 3.601 \\
Condomínio Dom Avelar Brandão Vilela \\
Bloco 18, apto. 403 - Bairro Tabuleta \\
CEP 64018-901 - Teresina-Pl \\
e-mail: linagsantos@uol.com.br
\end{tabular}

